
\title{
Einseitige Beinschwellung
}

H. S. FüeßI

\author{
Die Pflegerin eines Altenheims ruft an, weil sie bei einem \\ 78-Jährigen mit leichter Demenz vom Alzheimer-Typ eine \\ Schwellung des gesamten linken Beins und eine livide Ver- \\ färbung des Fußes bemerkt hat (Abb. 1). Der Mann liegt \\ seit drei Tagen mit Fieber im Bett und hat vermehrt Husten. \\ Er gibt keine Schmerzen an.
}

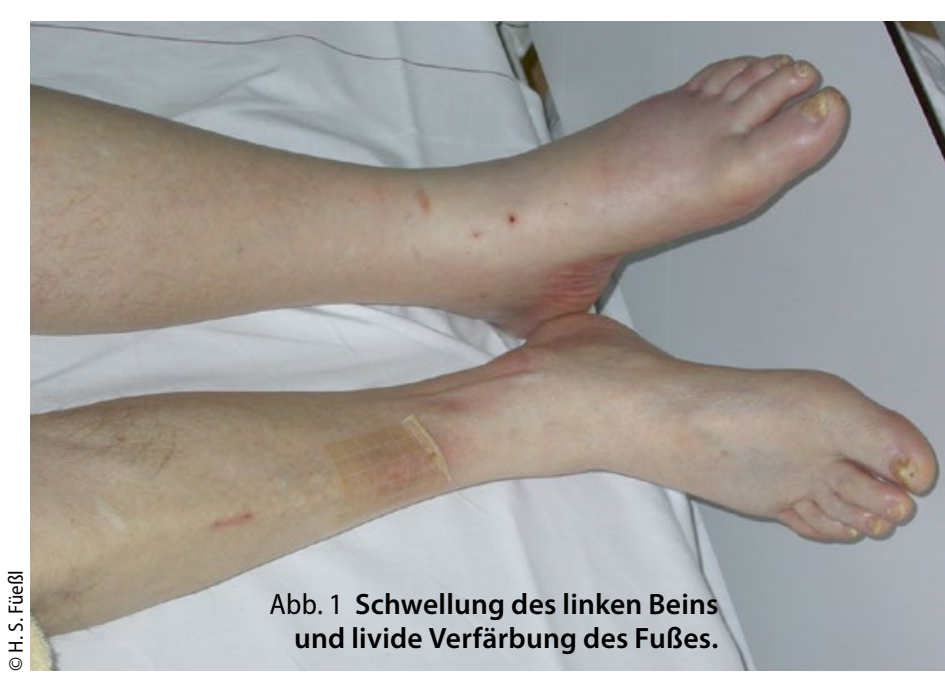

_ Für eine einseitige Beinschwellung gibt es viele Gründe. Das rasche Auftreten, die Risikosituation und die glänzende gespannte Haut lassen zuerst an eine tiefe Beinvenenthrombose (TVT) denken. Als Risikosituationen gelten:

- Langes Sitzen (z. B. Bus, Flugzeug)

- Bettlägerigkeit, Immobilisierung

- Exsikkose, Übergewicht

- OP am Bein (insb. TEP), Gips

- Defekte des Gerinnungssystems (Protein-S- oder -C-Mangel, APCResistenz, AT-III-Mangel)

- Tumorleiden, Schwangerschaft, Östrogene, Rauchen.

\section{Sofortdiagnostik}

Die klinischen Zeichen der TVT sind unsicher. Neben Ödem und Zyanose wurden Druckschmerz in der Kniekehle und Oberschenkel-Innenseite, Wadenschmerz bei Dorsalflexion des Fußes (Homans-Zeichen), Plantarschmerz auf Druck (Payr-Zeichen) und Wadenschmerz bei aufgepumpter Blutdruckmanschette (Lowenberg-Test) beschrieben. Diese Zeichen können vorhanden sein oder nicht, je nach Ausdehnung der Thrombose. Gerade bei bettlägerigen, allgemein kranken Patienten verläuft die Thrombose oft völlig asymptomatisch.

Eine Messung des Wadenumfangs im Seitenvergleich empfiehlt sich zur Dokumentation. Der Algorithmus der Diagnostik beinhaltet bei nicht bettlägerigen ambulanten Patienten zu Beginn ei- nen D-Dimer-Test. Ist er negativ, kann eine TVT ausgeschlossen werden.

Im o.g. Fall wurde auf den D-DimerTest verzichtet, da er bei Bettlägerigen häufig falsch positiv ist. Eine Kompressions-Sonografie im B-Bild kann klinisch relevante Thrombosen im Oberschenkelbereich mit hinreichender Sensitivität und Spezifität nachweisen bzw. ausschließen. Um Raumforderungen im Beckenbereich zu erkennen, sollte auch dieser sonografisch untersucht werden.

Mit einem mobilen Ultraschallgerät kann die Untersuchung schnell und einfach am Krankenbett erfolgen. Ansons-

Tab. 1 Empfohlene Dauer der Antikoagulation nach Risikosituation*

\begin{tabular}{|c|c|}
\hline 6 Wochen & $\begin{array}{l}\text { bei isolierter distaler tiefer } \\
\text { Beinvenenthrombose (TVT) }\end{array}$ \\
\hline $\begin{array}{l}3-6 \\
\text { Monate }\end{array}$ & $\begin{array}{l}\text { bei erster, sekundärer } \\
\text { proximaler TVT }\end{array}$ \\
\hline 6 Monate & $\begin{array}{l}\text { bei Lungenembolie, bei idio- } \\
\text { pathischer proximaler TVT }\end{array}$ \\
\hline 12 Monate & bei Rezidivthrombose \\
\hline Auf Dauer & $\begin{array}{l}\text { bei persistierendem Risiko } \\
\text { (aktives Malignom, schwere } \\
\text { klinische Thrombophilie, be- } \\
\text { sondere molekulare Throm- } \\
\text { bophilie) }\end{array}$ \\
\hline \multicolumn{2}{|c|}{$\begin{array}{l}\text { *Alle Empfehlungen können modifiziert werden, } \\
\text { etwa durch Präferenz des Patienten, Alter, Begleiter- } \\
\text { krankungen, Rezidivwahrscheinlichkeit und zeitlich } \\
\text { limitierte Risikoerhöhung. }\end{array}$} \\
\hline
\end{tabular}

ten muss man den Patienten in die Nothilfe eines Krankenhauses bringen.

\section{Therapie}

Bei klinischem Verdacht kann niedermolekulares Heparin verabreicht werden. Wird die Thrombose ausgeschlossen, beendet man diese Therapie wieder. Beim Nachweis einer Thrombose setzt man die Behandlung gewichtsadaptiert über mindestens fünf Tage fort und beginnt gleichzeitig überlappend mit einer oralen Antikoagulation mit Marcumar oder einem der neuen Antikoagulanzien. Die Dauer der Antikoagulation richtet sich nach der Ausdehnung der Thrombose und der Risikosituation (Tab. 1). Zusätzlich sollte man die betroffene Extremität entweder mit einer elastischen Binde oder einem Kompressionsstrumpf komprimieren. Bettruhe ist bei Unter- und Oberschenkelthrombosen nicht erforderlich.

\section{Woran noch denken, was noch tun?}

Eine Überwachung des Patienten empfiehlt sich wegen des LungenembolieRisikos. Man könnte auch ein EKG ableiten, um es bei späteren Befunden als Vergleich vorliegen zu haben.

\section{$\rightarrow$ Anschrift des Verfassers:}

Prof. Dr. med. Hermann S. FüeßI Internist und Gastroenterologe Privatpraxis für Integrative Innere Medizin Renatastr. 30, D-80639 München E-Mail: hsfuessl@t-online.de 